\title{
Research on the Value of Tesla Inc. based on Three Valuation Methods
}

\author{
Yifei Jiang ${ }^{1, a}$, Ziyan $\mathrm{Shi}^{2, \mathrm{~b}}$, and Tianchen $\mathrm{Li}^{3, \mathrm{c}}$ \\ 1. School of America, University of Nebraska Lincoln, Lincoln 68508, America \\ 2. School of China, Yixing High School, Jiangsu 214200, China \\ 3. School of China, senior high school attached to Shandong Normal University, Jinan 694337, \\ China \\ a847214731@qq.com, b3288767495@qq.com, c442471462@qq.com
}

\begin{abstract}
This article describes how to use three different methods to estimate whether Tesla is worth investing, and each method has been accurately calculated and speculated. In the introduction part, Tesla's current situation and history are addressed. In the theoretical framework, WACC, DCF, and Multiple method are discussed in turn, and they take different approaches. In the WACC section, the author uses a lot of data and context; in the DCF section, various terms are adopted; in multiple methods, the author makes a few tables for clarity. Finally, compared with the market value, Tesla's actual value is overestimated. The reference section summarizes all the data sources mentioned above.
\end{abstract}

Keywords: TASLA; WACC; DCF; Multiple Method; Overvalued.

\section{Introduction}

It is well known that our money will be devalued all the time due to inflation, which means that tomorrow's money is worth less than today's money, and the same amount of money can buy fewer and fewer things. Therefore, we can't sit still and wait for death, we should take the initiative to let the money flow in the market, so that out money is not reduced but more effect. In addition to putting money in the bank with interest, another effective way to make money grow is to invest.

However, each investment has risk. Tesla may be a stock that is often active in people's eyes. Since Tesla launched its first car into space in 2018, it has been on the news. In 2021, after Elon Musk announced Tesla with bitcoin, it appeared more frequently in various economic reports. Compared with other companies' stocks, Tesla is undoubtedly more dangerous, because now its stock price is very high. Some analysts are optimistic about its development prospects, while others hold negative view. So what is the future of Tesla? We use WACC, DCF method and multiple method to analyze Tesla, and finally get the result that Tesla is overvalued. The overall data for Tesla whatever WACC, stock price or current trading multiples are much higher than other Auto company, even Apple.

According to the Refinitiv data, the electric-car maker delivered 184,800 vehicles during the first quarter, above estimated of 177,822 vehicles. And as Tesla Inc first-quarter deliveries beat Wall street estimates on April 2, Wedbush Securities has upgraded its outlook for Tesla Inc[1]. (Akanksha Rana Reuters \& Arunima Kumar Reuters, 2021)On Sunday, Wedbush raised its price target for Tesla, from $\$ 950$ to $\$ 1,000$ a share[2]. (Mike Murphy, 2021) And the long-term bull-case price of $\$ 1,300$ per share. Tesla shares closed Thursday, April 1 at $\$ 661.75$ (markets were closed Friday), which means the company's share price is expected to rise more than $50 \%$ over the next 12 months. Wedbush Securities' analyst Daniel Ives and his team also believe the profitability of Tesla will improve significantly in the next three to four years, with earnings per share expected to reach $\$ 20$ by 2026 [3]. (2020) Ives and his team also see Tesla's profitability significantly improving over the next three to four years. Tesla shares are down $6.2 \%$ year to date, but have skyrocketed $628 \%$ over the past 12 months.

As a company which produces and sells electric vehicles, vehicle's delivery is a good judgement for people can see it easily and easier to understand. But in fact, the financial data shows that the main source of its profit is not from the sale of vehicles, but from the sale of carbon emission quotas to 
other traditional fuel vehicle manufacturers. From an economic point of view, we have some more complex valuation theory to judge the quality of a company. For example, WACC, DCF method and multiple approach.

Although many securities are particularly optimistic about Tesla's prospects, we think the market has a high valuation of Tesla. Then we will use the value method introduce above to show why we said that.

\section{Theoretical Framework}

\subsection{WACC}

Tesla is an American electric vehicle and energy company, produces and sells electric vehicles, solar panels and energy storage equipment. It founded by Martin Eberhard and Marc Tarpenning on July 1, 2003. The founder named the company "Tesla" in memory of physicist Nicolas Tesla. In 2004, Elon Musk joined the company and led round a financing. In 2020, Tesla achieved an operating profit of $\$ 1.994$ billion and a net profit of $\$ 721$ million. It's also the first time Tesla has made a full year profit. That means Tesla has been losing money in the past 16 years.

$W A C C$ is the abbreviation of weighted average cost of capital. It is a calculation of a firm's cost of capital in which each category of capital is proportionately weighted. All sources of capital, including common stock, preferred stock, bonds, and any other long-term debt, are included in a $W A C C$ calculation. Since the cost of capital is the return that equity owners (or shareholders) and debt holders will expect, WACC indicates the return that both kinds of stakeholders (equity owners and lenders) can expect to receive. Put another way, WACC is an investor's opportunity cost of taking on the risk of investing money in a company. A firm's WACC increases as the beta and rate of return on equity increase because an increase in WACC denotes a decrease in valuation and an increase in risk. It can be used as a hurdle rate against which companies and investors can gauge ROIC performance. WACC is commonly used as the discount rate for future cash flows in $D C F$ analyses.

As WACC is calculated by multiplying the cost of each capital source (debt and equity) by its relevant weight, and then adding the products together to determine the value, company directors often use WACC internally to make decisions (for example: determining the economic feasibility of mergers and other expansionary opportunities). A firm's $W A C C$ is the overall required return for a firm. And the return of project financing must be higher than the $W A C C$, otherwise the project has no investment value. So higher WACC means harder to achieve.

Here are some data for Tesla for 12/20/2020 on Yahoo Finance: (We will use them in the calculation of WACC for Tesla.) Market value of the firm's equity: 23,075 million, Market value of the firm's debt:13,279 million, Income tax expense: 115 million, income before taxes: 1,154 million, Income statement: 748 million [4]. (Yahoo Finance, 2020)

Then we can use simple calculation to get Corporate tax rate (income tax expense/income before taxes) is $9.96 \%$ and Cost of debt (interest expense/Market Value of debit) is $5.63 \%$. Total market value of the firm's financing is equal to Market value of the firm's debt add Market value of the firm's equity, and it equal to 36,354 million.

We found the Market Risk Premium and Risk-free Rate for U.S. in 2020 to get the Cost of equity (Beta*Market Risk Premium+ Risk-free Rate) which is $13.83 \%$ [5]. (Carla Nunes \& James P. Harrington, 2020) In the calculation of cost of equity, we use the beta found on 3/12/2021, which is 2.06. However, when we write this essay (4/5/2021), we find the beta for Tesla drop down to 2.01 [6]. (Yahoo Finance, 2021)

So, what's that means? Firstly, let we introduce what is beta. Beta value is a kind of risk index, which is used to measure the price fluctuation of individual stocks or stock funds relative to the whole stock market. The higher the value of $\beta$, the greater the volatility of the stock relative to the benchmark, and vice versa. When $\beta>1$, it means that the return and risk of the stock are greater than that of the index. For Tesla, whatever for Mar. 12 or Apr. 5, the beta is much higher than 1. It means the risk for Tesla's stock is very high. 
Now, maybe some people want to ask why the beta for decrease and what that means. Let we analysis the cause of this situation. In 2/8/2020, Elon Musk disclosed that Tesla has invested \$1.5 billion in bitcoin and intends to start accepting payments in bitcoin. Bitcoin is a very unstable existence, even though it increased by $300 \%$ in 2020 [7]. On March 14, bitcoin, which once broke through $\$ 60,000$, jumped rapidly, falling more than $3 \%$, and prices fell more than $\$ 2,000$. And on Mar 15, Bitcoin briefly jumped above $\$ 61,000$ to hit all-time highs. As higher beta means more risk, we think the beta for Tesla on March 15 may influence by the bitcoin. And as the WACC has a positive correlation with beta, the decrease for beta will cause the decrease for WACC. When we do the calculation for WACC in the middle of March, we get WACC is $10.63 \%$. So now, as the decrease of beta, the WACC will also be decrease. And then we found the high WACC for Apple is $9.7 \%$. And the BMW's high WACC is 7.7\% [8]. Apple is high-tech company in the United States. Apple's annual turnover is $\$ 260.174$ billion. And Tesla's annual turnover in 2020 is $\$ 24.578$ billion. As Apple's stock price is $\$ 125.90$ on $4 / 5 / 2020$, Tesla's stock price is 691.05 . From this comparison, we can see the stock price and WACC for Tesla is high.

Some people may think Apple is not an Auto company, those compare is not reasonable, so now let we use the BMW's WACC to compare. As we write above, BMW's high WACC is 7.7\% [8]. We can see the WACC for Tesla is much higher than WACC. So maybe we can say the lower WACC for Tesla will be more reasonable. As we write above, the WACC for Tesla is decrease with the decrease of beta from March 12 to April 5 and the stock price also decrease from 693.73 to 691.05 , we think lower stock price for Tesla is more reasonable. In other words, Tesla is overvalued now.

\subsection{DCF}

Before the $20^{\text {th }}$ century, the stock market was regarded as a casino, and no one thought trading stocks was a serious profession. It was not until the 1930s that Williams form Harvard University wrote a paper called "Theory of Value Investment." He proposed that stock is also a commodity with intrinsic value, which is the sum of the discounted cash flow that an enterprise can create in the future, and represents the value that an enterprise can create for its shareholders. After this theory was put forward, Graham, the father of value investing, also put forward a theory called the price-to-earnings ratio valuation theory. These two theories became the beginning of value investment in the stock market. Since then, all the people who advocate value investment will attach great importance to the internal value of this kind of enterprise.

$D C F$ is a valuation method which is used to estimate the value of an investment based on its expected future cash flows. In simpler word, DCF analysis attempts to figure out the value of an investment today, based on projections of how much money it will generate in the future. For example, according to this model, investors can infer whether the stocks they buy will go up or down and whether they will make a profit, while employers can use the model to decide whether their companies should be adjusted.

However, because WACC needs more analysis and judgment, there are more changes and uncertainties. Because Tesla is a relatively large tram enterprise in the world, and the data in all aspects are relatively perfect, it is more intuitive to calculate the company value by DCF valuation method.

$D C F$ is an impeccable valuation model in theory, which is especially suitable for industries with high predictability of cash flow, but for industries with frequent and unstable cash flow, the accuracy and credibility of $D C F$ valuation will be reduced. In practical application, it is very difficult to accurately predict the cash flow in the next decade. Generally, $D C F$ is regarded as the most conservative valuation method, and its valuation result will be the bottom line of the target price. For investors, no matter which valuation standard is used to price the stock, DCF model will help to form a quantitative grasp of the long-term development of the invested company. So now, let we use $D C F$ method to analysis Tesla.

There are eleven stages to calculate $D C F$. First of all, past revenue needs to be found out, and we usually consider the income of the last three years. The more data, the better, but it also complicates 
the process. Then, according to the trend of revenue and the situation of the company, the future revenues can be inferred Second, we should calculate the growth rate of revenue with the revenue of two consecutive years, and then judge the future growth rate by the past growth rate of revenue. The revenue growth rate can be calculated by subtracting the first year's revenue from the second year's revenue and dividing it by the first year's revenue. Third, find the past operating profit(earnings before interest and tax)(EBIT), and then divide the EBIT by the revenue to get the operating margin. Using the same algorithm to calculate the operating margin, we can also infer the further operating margin. After we have the future operating margin, we can get the EBIT by multiplying it by the revenue. Fourth, find the average tax revenue of the company, which is usually included in the company's financial report. Multiply the future EBIT by tax rate, and then be subtracted by the original EBIT to get earnings before interest, tax, depreciation and amortization(EBITDA), which is the purest income of the company. Fifth, find the company's depreciation and amortization, and infer the value of the next few years according to the trend of previous years. Then, capital expenditure $(C A P E X)$ and change in nonworking capital $(N W C)$ can be deduced in the same way. The sixth stage is to calculate free cash flow $(F C F)$. When calculating $F C F$, we need to take all the above values into account. $F C F$ can be obtained by subtracting CAPEX and change in NWC from EBITA plus depreciation plus amortization. The seventh step is to calculate present value $(P V)$, adding 1 to the above-mentioned $W A C C$, and then get the value to the power of the year. Finally, divide the $F C F$ just calculated by this value, and $P V$ is calculated, then sum all the future $P V$. Year power means that the first year in the future is the first power, the second year in the future is the second power, and so on. Eighth, estimate the growth rate of the company. Generally speaking, the growth rate is lower than the revenue growth rate judged above, because according to common sense, no company can grow at a high growth rate for a long time. Theoretically, in the short term, it is possible to let the growth rate more than WACC, but in the long run, enterprises will not allow this kind of situation, because enterprises will continue to be negative and unprofitable, so they may launch or change strategies. In the assumption of this model, there is an infinite period, so the growth rate is greater than that of WACC. As a result, we need to estimate a number which is smaller than WACC. Ninth, the terminal value is obtained by multiplying the estimated cash flow of the last year by the sum of one plus the growth rate, and then dividing this value by the difference between WACC and the growth rate. Tenth, PV terminal value can be obtained by dividing terminal value by one and adding the year power of WACC. The last step is to add $P V$ terminal value and sum of $P V$ to get the final total value. We can find the market value of the company on the Internet. If the value is greater than the total value calculated by us, it is overvalued or the company is really good. If it is less than the total value, it is undervalued or the company is really bad. The next step is not necessary, but it is better. Add cash to the total value minus debt to get equity value, and then compare equity value with market capital. The comparison method is opposite to the above, if the equity value is greater than the market capital, it means under value, and vice versa.

In the company Tesla, its tax revenue is about $15 \%$ and the growth rate is 3\% [9]. Because Tesla has a good prospect as an electric vehicle, but it is controversial recently, so the growth rate is medium, at $3 \%$. The total value of the next five years is about $3.976294 * 10^{\wedge} 11$, the market value is 6.26938 $* 10^{\wedge} 11$. So the total value is smaller than the market value, so Tesla is overvalued.

\subsection{Multiple Method}

To make the research more accurate, we also want to use Multiple method to analysis. Multiple method is a valuation theory based on the idea that similar assets sell at similar price. It assumes that a ratio comparing value to a firm-specific variable, such as operating margins, or cash flow is the same across similar firms. Generally, multiple is a genetic term for a class of different indicators that can be used to value a stock. A multiple is simply a ratio that is calculated by dividing the market or estimated value of an asset by a specific item on the financial statements. The multiples approach is a comparable analysis method that seeks to value similar companies using the same financial metrics. The idea behind the multiples analysis is that when firms are comparable, the multiples approach can 
be used to determine the value of one firm based on the value of another. What 's more, the multiples approach seeks to capture many of a firm's operating and financial characteristics in a single number that can be multiplied by a specific financial metric to yield an enterprise or equity value. There are many ways to compare different data to get the result that the company is overvalued or not, such as enterprise-value-to-sales ratio, EV to sales, EV to EBIT and so on, which will be further explained one by one.

In fact, we use multiple method when we discuss for WACC because the approach for multiple method is comparing. But now, let we see some comparation more economics. We use the data found online to do comparing with Tesla and different companies. Multiple method is very suitable to make valuation for Tesla, maybe is the most suitable one, just because its data are so special, even can be regarded as surprising. There are several datas of Tesla's financial report (got from Finbox) can show the difference between Tesla and other companies.[8]

Table 1. Stock price and P/E ratio comparing

\begin{tabular}{|c|c|c|}
\hline & stock price & P/E ratio \\
\hline AAPL & 120.53 & $31.7 \mathrm{x}$ \\
\hline AMZN & 3.028 & $71.5 \mathrm{x}$ \\
\hline F & 12.49 & $-38.9 \mathrm{x}$ \\
\hline GM & 59.27 & $13.7 \mathrm{x}$ \\
\hline HNDA.F & 30.59 & $13.9 \mathrm{x}$ \\
\hline TOYO.F & 79.63 & $15.1 \mathrm{x}$ \\
\hline TSLA & 653.16 & $908.6 \mathrm{x}$ \\
\hline
\end{tabular}

There are several famous companies in the same industry, scientific and technique company Apple, Amazon, also some manufacturing companies, Honda, Toyoda, and Tesla. The stock price are similar, However, concerning the P/E ratio, Tesla's is way too bigger than other companies'. P/E ratio is one of the most commonly used measures to assess whether stock prices are at a reasonable level. The normal number is around 10X, but Tesla's is $908.6 \mathrm{X}$. Generally, when a company's P/E ratio is very high, there will be two situations about the company. The first one is people have a very high expectation to this company, and the second one is this company is overvalued. Tesla as a manufacturing company, its $P / E$ ratio is almost 90 times as Toyoda and Honda's. It is certain that Tesla has some differences from traditional manufacturing companies because it uses clean energy and it has automatic navigation system, which are advanced technologies. In that case, we can also compare Tesla with Apple and Amazon. However, the result is the same.

Table 2. Price/LTM sales comparing

\begin{tabular}{|c|c|}
\hline & Price/LTM sales \\
\hline AAPL & $6.9 \mathrm{x}$ \\
\hline AMZN & $3.9 \mathrm{x}$ \\
\hline F & $0.4 \mathrm{x}$ \\
\hline GM & $0.7 \mathrm{x}$ \\
\hline HNDA.F & $0.4 \mathrm{x}$ \\
\hline TOYO.F & $0.9 \mathrm{x}$ \\
\hline TSLA & $19.9 \mathrm{x}$ \\
\hline
\end{tabular}

This is another data (from finbox) of comparison between the same companies as the previous data. From this form, we focus on the Price/LTM Sales. Price/LTM Sales is a standard to measure whether the company is merit for investors to invest money. The lower Price/LTM Sales, the more valuable for invertors to invest. Tesla as a new listed company, it is impossible to have such a high Price/LTM Sales. 
Table 3. EV/EBIDA COMPARING

\begin{tabular}{|c|c|c|c|c|c|c|}
\hline & GM & F & HNDA & TOYO.F & AMZN & TSLA \\
\hline 5Y CSGR & $-2.5 \%$ & $1.6 \%$ & $2.3 \%$ & $1.9 \%$ & $25.8 \%$ & $50.4 \%$ \\
\hline 3Y CSGR & $-2.7 \%$ & $0.9 \%$ & $2.2 \%$ & $2.7 \%$ & $27.3 \%$ & $52.0 \%$ \\
\hline EV/EBITDA & $15.3 \mathrm{x}$ & $27.5 \mathrm{x}$ & $9.2 \mathrm{x}$ & $4.7 \mathrm{x}$ & $37.7 \mathrm{x}$ & $155.2 \mathrm{x}$ \\
\hline
\end{tabular}

This is a data I got from professor's lecture. Companies are the same as above, but data we used to compare are different. In the second line, the 5 years Compound Annual Growth Rate means the annual growth rate of an investment over 5 years. It is worth noting that $C A G R$ is not the same as the real value of $G R$ (Growth Rate). The purpose described by $C A G R$ is to convert the Rate of return of investment into the expected value of a relatively stable return on investment. We can think that $C A G R$ smooths the return curve and will not be lost by short-term dramatic changes in return. Annual growth rate is a short-term concept. From the perspective of the development of a product or industry, it may be in the growth or explosion period and the annual results vary greatly. However, if measured by compound growth rate, it can better explain the potential and expectation of the growth or change of an industry or product, because it is based on a long-term period of time. Tesla's 5 years CAGR and 3 years $C A G R$ are way too higher than other companies'. What's more, when we look at the EV/EBITA, EV/EBITDA multiple and P/E both belong to the comparable method. The methods and principles used are similar and slightly different, but the selected index calibers are different. From the calculation of indicators, the EV/EBITDA multiple uses enterprise value $(E V)$, that is, the market value of all the capital invested in the enterprise replaces the stock price in $P E$, and the earnings before interest, tax, depreciation (EBITDA) replaces the net profit per share in $P E$. The capital input of all investors in an enterprise includes both shareholders' equity and creditors' input, and EBITDA reflects the pre-tax income level obtained by all investors mentioned above. Whereas $P E$ is the ratio of stock market capitalization to forecast net profit, EV/EBITDA reflects the proportional relationship between the market value of invested capital and corporate earnings in the coming year.

Therefore, in general, both $P E$ and EV/EBITDA reflect the proportional relationship between market value and earnings indicators, but $P E$ is from the perspective of shareholders, while EV/EBITDA is from the perspective of all investors. By looking at the data, Tesla's EV/EBITDA is also very high.

\section{Conclusion}

Tesla is not like those small companies, who have the risk of insufficient data or failure to operate. On the contrary, Tesla, as a new car, is highly praised by the majority of customers. Moreover, Tesla's data is very perfect. With so many data support, the subjective consciousness of valuers will be greatly reduced and the objective effect will be achieved. Therefore, the risk of miscalculation of future cash flow is relatively small.

Tesla has a very expectant future, but its' data are so overblown, so it is overvalued.

\section{References}

[1] Akanksha Rana Reuters \& Arunima Kumar Reuters, (April 2021), Tesla first-quarter deliveries beat estimates, Tesla first-quarter deliveries beat estimates | Nasdaq.

[2] Mike Murphy, (2021), Tesla stock upgraded by Wedbush after 'paradigm changer' delivery numbers, Tesla stock upgraded by Wedbush after 'paradigm changer' delivery numbers | Morningstar.

[3] (2020), Tesla STOCK TO BE ADDED ALL AT ONCE TO S\&P 500, Tesla stock to be added all at once to S\&P 500 - ValueWalk.

[4] Information on: https://finance.yahoo.com.

[5] Carla Nunes \& James P. Harrington, (2020), Duff \& Phelps Recommended U.S. Equity Risk Premium Decreased from 6.0\% to 5.5\%, Effective December 9, 2020, Duff \& Phelps Recommended U.S. Equity Risk Premium Decreased from 6.0\% to 5.5\%, Effective December 9, 2020 (duffandphelps.com). 
[6] Information on: https://finance.yahoo.com.

[7] (2021), Bitcoin in 2020 rose in price almost by $300 \%$, is it a Fact?, Bitcoin in 2020 rose in price almost by $300 \%$, is it a Fact? | BITCOIN AND COMMUNITY MEMBERS (bitcoinmembers.com).

[8] Information on: https://finbox.com.

[9] Information on: https://finance.yahoo.com. 